\title{
Kinerja Public Area Attendant di saat Full Event di Hotel Batiqa Pekanbaru
}

\author{
ELTI MARTINA \\ Sekolah Tinggi Pariwisata Riau \\ Jl. Pattimura No. 54, Cinta Raja, Sail, Cinta Raja, Kec. Sail, Kota Pekanbaru, Riau 28127 \\ E-mail : eltimartina@gmail.com
}

\begin{abstract}
The hotel management must think of a strategy so that employees are able to work in accordance with what is expected to support the success of the goals to be achieved. Possible efforts must be made by Batiqa pekanbaru Hotel is by increasing the number of employees so that when the Hotel is in full and moderate Occupancy the number of events that take place does not make employees feel depressed on the work that must be done. Through this type of descriptive research, information is obtained that the Public Area Attendant at Hotel Batiqa Pekanbaru has two tasks to do, namely as Roomboy and as a Public Area Attendant that makes Public Area employees have workloads that make the Public Area's performance ineffective. Factors in lack of equipment and also a lack of employees resulted in a decrease in the performance of Public Area employees.
\end{abstract}

Keywords: Public Area Attendant, Full Event

Pertumbuhan hotel di kota Pekanbaru sebagai Ibukota Provinsi Riau kian marak, sejalan dengan maraknya event nasional yang telah digelar dan telah menjelma menjadi salah satu kota tujuan bisnis di pulau sumatra. Seperti acara PON, kemudian pekan Paralampik Nasional dan beberapa acara telah menarik hati para penyedia bisnis jasa terutama dibidang jasa akomodasi didaerah yang dijuluki sebagai "kota bertuah".

Pertumbuhan ekonomi di Riau yang kuat dan masih akan tetap tumbuh, diperkirakan masih menjadi penarik hati investor untuk menyediakan akomodasi yang lebih baik lagi.

Kemudian ditopang oleh Riau yang di kenal sebagai daerah penghasil minyak dan gas bumi (migas), serta dua raksasa perusahan kertas, lalu perkebunan kelapa sawit dan karet, tambang batubara dan lainlain.

Hotel adalah bagian yang menyediakan kamar untuk menginap para tamu, makanan dan minuman serta fasilitas-fasilitas lain yang diperlukan dan dikelola secara profesional untuk mendapatkan keuntungan. (Rumekso, 2011)

Hotel adalah suatu bentuk akomodasi yang dikelola secara komersil, disediakan bagi setiap orang yang memperoleh pelayanan dan penginapan berikut makan dan minuman. (SK Menteri Perhubungan No. Pm 10/Pw.301/phb. 77.) Housekeeping memberikan pelayanan terhadap kelancaran, kesiapan dan pemeliharaan kamar tamu, public area, restaurant, meeting room, laundry, sarana olahraga dan fasilitas lainnya. Mereka merupakan bagian dari team yang selalu siap mempersiapkan dan menyambut kedatangan tamu hotel. Housekeeping sangat peduli terhadap kenyamanan tamu dengan cara memperhatikan hal - hal yang detail dan menindaklanjuti segala perbaikan perbaikan yang diperlukan.

Dalam oprasional hotel hal - hal mengenai kebersihan dilakukan oleh department housekeeping yang kegiatannya tak jauh beda dengan pembantu, tapi secara umum housekeeping memiliki tanggung jawab area yang besar, maka wajar 
jika housekeeping mempunyai jumlah karyawan lebih banyak dari department lain. Oleh sebab itu karyawan Housekeeping department harus memiliki skill dan menguasai ruang lingkup kerja supaya dapat menjaga stabilitas kerja di departmen Housekeeping .

Tamu-tamu yang akan menginap di hotel biasanya akan memilih hotel-hotel yang mempunyai kamar-kamar yang memenuhi standar yaitu kamar yang bersih, rapi, nyaman, dan aman serta pelayanan yang baik dari Roomboy.

Hotel Batiqa Pekanbaru merupakan salah satu hotel yang terletak di pusat kota Pekanbaru. Hotel ini memiliki tingkat hunian yang tinggi dan menjadi favorit tamu luar kota yang ingin berlibur atau melakukan pekerjaan atau sekedar menginap di Hotel Batiqa. Hotel ini adalah hotel yang paling dekat dengan bandara Sultan Syarif Qasim II yang ada di Pekanbaru.

Karyawan Housekeeping di Hotel tidak melulu selalu mengerjakan tugasnya dengan baik, seperti karyawan Public Area yang biasanya mengerjakan area Hotel namun peralatan yang ada kurang memadai. Banyaknya tamu yang menginap di Hotel Batiqa Pekanbaru membuat karyawan Public Area harus bekerja lebih ekstra agar area yang sering dikunjungi oleh tamu tetap terlihat nyaman, bersih, dan rapi.

Adapun kendala yang dialami oleh Hotel Batiqa Pekanbaru adalah tentang kinerja karyawan Public Area terhadap beban kerja yang harus dilakukan. Banyaknya Event yang dilaksanakan di Hotel Batiqa Pekanbaru membuat motovasi kerja dari karyawan tersebut menjadi menurun sehingga mengakibatkan pekerjaan yang harus dilakukan menjadi tidak efektif terhadap perusahaan.

Beban kerja yang menjadi tanggung jawab Pubic Area Attendant tidak sesuai dengan porsi pekerjaan yang harus dilakukan. Terlebih saat banyaknya Event dan Occupancy Hotel sedang penuh membuat karyawan Public Area menjadi sangat sibuk sehingga membuat kinerjanya menurun.

Karyawan di Hotel Batiqa Pekanbaru seluruhnya harus memiliki motivasi kerja yang tinggi demi menunjang keberhasilan target yang harus di capai. Dengan demikian kinerja dari karyawan menjadi baik untuk menjaga tingkat hunian Hotel dan agar menghindari komplain yang mungkin akan sering terjadi apabila tidak segera berbenah.

Berikut adalah data yang penulis peroleh dari Hotel Batiqa Pekanbaru terkait banyaknya Event yang berlangsung selama 6 (enam) Bulan penulis melakukan Training.

Menurut Rumekso (2002) Hotel sangat berperan aktif dalam memajukan industri pariwisata. Menurut Sulastiono (2011), hotel adalah suatu perusahaan yang dikelola oleh pemiliknya dengan menyediakan pelayanan makanan dan minuman, fasilitas kamar untuk tidur kepada orang-orang yang melakukan perjalanan dan mampu membayara dengan jumlah yang wajar sesuai dengan pelayanan yang diterima tanpa adanya perjanjian khusus.

Public area berasal dari kata public dan area yang mempunyai arti masingmasing yaitu : Public adalah umum dan area adalah area, kawasan, atau daerah. Jadi Public Area itu berarti area umum atau daerah umum, kawasan umum. Jadi area umum itu area yang dapat dilalui oleh siapa pun tanpa terkecuali.

Menurut Yulia Novita (2016) Syarat-syarat yang harus dipenuhi oleh seorang pegawai hotel yang bekerja dibagian Public Area adalah sebagai berikut: Jujur (Honesty), jujur terhadap diri sendiri, terhadap sesama karyawan, terhadap atasan, maupun terhadap perusahaan; Disiplin dan tepat waktu, baik saat kedatangan ketempat tugas, saat bekerja, maupun saat meninggalkan tempat tugas serta setelah menyeleaikan tugas pekerjaan yang diberikan oleh atasan didalam hotel; Sehat jasmani dan Rohani 
(phisical and mental health), dapat menerima job description maupun instruksi dari atasan, menjabarkan, dan melaksanakannya dengan baik dan benar; Kebersihan pribadi (Personal Hygiene), minimal mandi dua kali sehari, tidak berbau rokok, bau badan tidak menyengat; Tertarik terhadap pekerjaan (interest to the job), mencintai pekerjaan seberat apapun, menyelesaikannya dengan baik; Tanggung jawab (responsibility), dapat menyelesaikan pekerjaan dengan baik, dengan penuh tanggung jawab, apapun resikonya; Sikap dan prilaku yang sopan santun (attitude and courteous), baik terhadap teman sekerja, atasan, tamu hotel; Penampilan (performance), mengenakan pakaian seragam yang disetrika rapi, rambut dicukur dan disisir rapi, tidak berkumis, berjanggut dan berjambang. Sepatu disemir mengkilap dan tidak memakai perhiasan berlebihan; Percakapan (intelligency), cakap dan terampil dalam menyelesaikan tugas serta dapat mengatasi kendala-kendala yang terjadi didalam menunaikan tugas dan pekerjaannya; Ramah (friendliness), terhadap semua karyawan, atasan, dan kepada para tamu; Setia (loyality), terhadap perusahaan, terhadap pekerjaan yang dihadapi dan dikerjakannya setiap hari, karena merupakan sumber pendapatan dan sumber penghidupan baginya; Hormat (respect), terhadap karyawan, atasan, para tamu maupun pekerjaan dan perusahaan, kemudian menimbulkan sikap setia kepada perusahaan; Selalu berfikir positif (positif thingking), tidak menaruh curiga kepada teman sekerja, atasan, para tamu, walaupun harus waspada terhadap kemungkinan yang terjadi; Bekerja tidak menonton, tetapi penuh inisiatif dan kreatif untuk menciptakan metode ataupun cara baru agar pekerjaan dapatb diselesaikan dengan baik dengan hasil yang lebih baik, efektif dan efesien (creative,initiative, and innovative); Melakukan kebiasaan yang baik (good habbit), dalam melakukan tugas sehari-hari, mulai dari persiapan sampai dengan akhir penyelesaian tugas, harus dilakukan secara terprogram.
Kinerja karyawan sering diartikan sebagai pencapaian tugas, dimana karyawan dalam berkerja harus sesuai dengan program kerja perusahaan untuk menunjukan tingkat kinerja karyawan dalam mencapai visi misi dan tujuan perusahaan.

Menurut Mathis (2002) kinerja karyawan adalah yang mempengaruhi seberapa banyak mereka memberikan kontribusi kepada organisasi antara lain termasuk: Kuantitas kerja, Standar ini dilakukan dengan cara membandingkan antara besarnya volume kerja yang seharusnya (standar kerja normal) dengan kemampuan sebenarnya; Kualitas kerja, Standar ini lebih menekankan pada mutu kerja yang dihasilkan dibanding volume kerja; Pemanfaatan waktu, Yaitu penggunanaanmasa kerja yang disesuaikan dengan kebijaksanaan perusahaan.

Faktor-faktor yang mempengaruhi karyawan dalam bekerja, yaitu kemampuan karyawan untuk melakukan pekerjaan tersebut, tingkat usaha yang dicurahkan, dan dukungan perusahaan. Kinerja karyawan berkurang apabila salah satu faktor ini berkurang atau tidak ada. Masalah kinerja merupakan hasil kerja yang dicapai seseorang dalam melaksanakan pekerjaan tugas dan tanggung jawab yang dibebankan kepada karyawan;

Kinerja karyawan secara objektif dan akurat dapat dievaluasi melalui tolak ukur tingkat kinerja. Pengukuran tersebut berarti memberi kesempatan bagi para pegawai untuk mengetahui tingkat kinerja mereka. Memudahkan pengkajian kinerja pegawai, lebih lanjut Mitchel dalam buku (Sedarmayanti, 2001) yang berjudul Manajemen Sumber Daya Manusia dan produktivitas kerja mengemukakan indikator-indikator kinerja yaitu sebagai berikut : Kualitas Kerja (Quality of work); Ketetapan waktu (Pomptnees); Inisiatif (Initiative); Kemampuan (Capability); adn Komunikasi (Communication).

Menurut Permendagri, Beban kerja adalah besaran pekerjaan yang harus dipikul oleh suatu jabatan atau unit 
organisasi dan merupakan hasil kali antara volume kerja dan norma waktu. (Permendagri, 2008)

Menurut Moekijat (2004), Beban Kerja adalah volume dari hasil kerja atau catatan tentang hasil pekerjaan yang dapat menunjukkan volume yang dihasilkan oleh sejumlah pegawai dalam suatu bagian tertentu.

\section{METODE}

Penelitian ini penulis lakukan di Hotel Batiqa Pekanbaru. Populasi penelitian ini melibatkan seluruh karyawan di di Hotel Batiqa Pekanbaru. Sampel adalah keseluruhan objek yang diteliti dan dianggap mewakili seluruh populasi yang menjadi sampel dalam penelitian ini adalah karyawan keseluruhan yang terlibat dalam Full Event adalah: 36 orang.

Data dikumpulkan dengan penyebaran angket dilakukan dengan cara membuat daftar pertanyaan kepada karyawan Housekeeping Hotel Batiqa Pekanbaru untuk memperoleh data mengenai upaya Public Area Attendant dalam menjaga kinerja terhadap beban kerja di saat Full Event di Hotel Batiqa Pekanbaru.

Dalam menganalisis data ini penulis menggunakan metode analitif yaitu dengan cara menganalisa data yang ada dan dihubungkan dengan data yang sebenarnya serta dirangkaikan dengan teori yang mendukung pembatasan masalah tersebut.

\section{HASIL}

Public area di dalam hotel adalah tempat-tempat yang sering dikunjungi dan dipergunakan oleh para tamu, baik tamu yang menginap maupun tidak menginap. Para tamu akan menilai dan mendapatkan kesan pertama dari yang mereka lihat dan mereka dapat dari public area ini. Kebersihan, kerapian keindahan, serta kenyamanan public area merupakan kesan pertama bagi para tamu, yang memberikan image bahwa hotel yang mereka datangi adalah hotel yang baik, yang dapat memberika kepuasan kepada tamu selama menginap di hotel tersebut.

Hotel Batiqa Pekanbaru khususnya di bagian Housekeeping memiliki 7 (tujuh) karyawan yang terdiri dari 6 (enam) Room Boy dan 1 (satu) Public area. Yang mana Public area di Hotel Batiqa pekanbaru pada saat operasional di hotel tersebut melakukan dua tugas yaitu, pada saat high season atau kondisi hotel dalam keaadan penuh dan juga bersamaan dengan banyaknya event yang ada di hotel Batiqa maka pekerjaan Public area yang pertama kali adalah membantu Roomboy membersihkan kamar tamu sampai pada saat jam makan siang. Setelah itu baru melakukan pengecekan ke area hotel atau ke area dimana event dilaksanakan. Dalam hal ini, jelas bahwa Batiqa hotel Pekanbaru khususnya di bagian Housekeeping Departemen memiliki masalah dalam menjalankan SOP yang seharusnya tugas dari Public area adalah merawat dan menjaga lingkungan hotel dan area-area yang sering di kunjungi oleh tamu, menjadi kurang efisien karena kurangnya sumber daya manusia (SDM) di hotel tersebut.

\section{Target yang harus dicapai}

Seorang karyawan public Area harus mampu melakukan apa yang seharusnya dikerjakan disaat operasional jam kerja. Oleh sebab itu, karyawan Public Area di Hotel Batiqa Pekanbaru harus mampu melaksanakan pekerjaan yang sesuai dengan SOP yang sudah diterapkan manajemen tersebut. Dalam mengerjakan suatu tugas, seorang karyawan Public Area harus mampu melakukan tugas dengan sebaik mungkin agar pekerjaannya selesai tepat waktu bahwa target pemakaian ruangan untuk Event dari bulan Februari bulan Juli adalah 196 kali, dan Event yang dapat Terealisasikan adalah 180 kali. Upaya yang pemasaran yang dilakukan Hotel Batiqa Pekanbaru terbilang Baik karena total Event yang terealisasi masih cukup tinggi.

\section{Kondisi pekerjaan}

Seorang karyawan Public Area harus mampu membaca kondisi pekerjaan, 
seperti di saat Full event, dan occupancy kamar sedang penuh, maka Public Area harus mampu mengerjakan pekerjaan ekstra diluar SOP nya sendiri. Dan ditambah dengan pekerjaan pembersihan diluar area gedung Hotel menurut responden Public Area terhadap kondisi kerja di Batiqa Hotel pekanbaru adalah Cukup Baik, dikarenakan disaat Full Event dan Occupancy kamar sedang penuh karyawan Public Area harus mampu mengerjakan pekerjaan disaat Full Event di ruang Meeting dan sebagai Roomboy disaat Occupancy kamar sedang penuh.

\section{Standar Pekerjaan}

Seorang karyawan Public Area harus mampu mengerjakan pekerjaan sesuai SOP yang telah diterapkan oleh manajemen Hotel Batiqa Pekanbaru. Saat Occupancy kamar sedang penuh dan juga banyaknya Event yang ada maka karyawan harus mampu menjaga kinerja dan menjalankan SOP pekerjaan dengan baik. SOP yang diterapkan manajemen di Hotel Batiqa Pekanbaru adalah Baik, dikarenakan SOP yang telah diterapkan oleh manajemen mampu menunjang pekerjaan yang tepat agar kinerja karyawan disaat Full Event menjadi efektif.

\section{PEMBAHASAN}

Beberapa hal yang mempengaruhi beban kerja sehingga mengakibatkan kinerja karyawan menurun adalah target yang harus dicapai, kondisi pekerjaan dan standar pekerjaan. Bagi karyawan meningkatnya target kerja yang mereka miliki mampu mempengaruhi kinerja mereka. Karyawan harus pandai mengatur pikiran mereka bisa menjaga kinerja kerja mereka. Standar pekerjaan yang harus mereka hadapi setiap harinya harus mampu mereka kerjakan sesuai target. Tidak semua karyawan mampu menangani beban kerja yang sama. Berlebihnya beban kerja yang dihadapi oleh karyawan mampu mempengaruhi kinerja mereka. Semakin tingginya beban kerja yang mereka hadapi akan menganggu penyelesaian kerja mereka.

Hambatan yang di alami Public Area pada saat menjalankan tugasnya adalah sebagai berikut :

Peralatan dan bahan pembersih

Minimnya peralatan yang dimiliki oleh perusahaan membuat terhambatnya kerja seorang Public Area pada saat menjalankan tugasnya. Begitu juga dengan bahan pembersih yang medukung. Pada saat membersihkan area tugasnya, seorang Pulic Area seharusnya menggunakan alat dan bahan pembersih yang mendukung sehingga mampu bekerja dengan baik.

\section{Luas Ruangan}

Selain alat dan bahan pembersih, Luas area yang dikerjakan oleh seorang Public Area juga menjadi faktor penting yang harus diperhatikan saaat melakukan pembersihan. Seorang Public Area harus mampu meminimalisir waktu yang harus ia kerjakan agar pekerjaan yang lain mampu di kerjakan dengan baik dan tidak terburuburu.

\section{Waktu yang dibutuhkan}

Waktu kerja yang efektif juga perlu di perhatikan bagi seorang karyawan. Sehingga karyawan mampu melakukan banyak pekerjaan berikutnya. Berikut adalah rumus waktu kerja yang efektif yang diambil dari situs pakarkerja.com.

Ada sekitar 4 (empat) waktu kerja yang efektif yaitu waktu kerja per hari, minggu, bulan, dan tahun. Rumus yang ditetapkan untuk rumus waktu kerja efektif per hari adalah 1 hari $\times 8$ jam $\times 60$ menit $=$ 480 menit.

Sehingga waktu kerja efektif yang berlaku setiap minggu adalah 5 hari $x 7$ jam x 60 menit $=2.100$ menit .

Sedangkan waktu kerja yang efektif untuk setiap bulan adalah 20 hari x 7 jam x 60 menit $=8.400$ menit.

Untuk waktu yang efektif yang ditetapkan setiap tahun adalah 240 hari $\mathrm{x} 7$ jam x 60 menit $=100.800$ menit. Bahwa penggunaan ruang meeting di Hotel Batiqa Pekanbaru dimulai dari bulan Maret-Juli di setiap ruangan meeting memiliki

e.ISSN. 2541-4356 
konsistensi penyewaan ruangan yang dilaksanakan hampir setiap hari dalam satu bulan.

Dan dapat disimpulkan bahwa dengan tingginya penggunaan ruangan untuk berbagai event dan jumlah karyawan yang minim maka kinerja karyawan akan menurun. Bahwa luas area meeting room yang ada di Hotel Batiqa Pekanbaru untuk Ruang Anselia I dan II yang memiliki lebar dan panjang yang sama sehingga membutuhkan waktu pembersihan selama 30 menit. Sedangkan untuk ruang Seri yang memiliki ukuran panjang dan lebar yang lebih kecil membutuhkan waktu pembersihan selama 15 menit .

Dari dapat terlihat dengan luas ruangan yang akan dibersihkan dan waktu yang tersedia dalam melaksanakan pada saat terjadinya full event sangat tidak efektif. Bahwa SOP kerja yang dilakukan karyawan Public Area dari mulai Prepare hingga sampai pelaksanaan membutuhkan waktu selama 30 menit. Dan dapat disimpulkan bahwa seorang karyawan Public Area harus mampu meminimalisir setiap pekerjaan yang dilakukannya agar dapat melakukan tugas lainnya.

Dalam menjaga kinerja terhadap beban kerja disaat full event karyawan public area harus mampu untuk berada di 2 ( dua ) lokasi yang pertama di public area dan yang kedua di roomboy. Dalam hal ini seorang karyawan public area sangat tidak efektif bekerja dalam dua bidang dan menjadi suatu beban kerja yang sangat tidak di inginkan

\section{Efektifitas dan Efesiensi}

Seorang karyawan Public Area dan yang terlibat didalam sebuah Event di Hotel Batiqa Pekanbaru harus mampu mengerjakan pekerjaan dengan efektif, agar mampu menghasilkan hasil kerja yang efisien. Sehingga pekerjaan yang dilakukan selesai pada waktu yang telah di tentukan.

Dari tabel responden karyawan di atas, Efektifitas dan Efesisensi kinerja karyawan Public Area di saat Event di Hotel Batiqa Pekanbaru adalah Tidak Baik, dikarenakan kinerja dari karyawan Public Area disaat Full
Event dan Occupancy Hotel sedang penuh, Public Area mampu mengerjakan tugasnya sebagai karyawan Public Area dan juga sebagai seorang Roomboy disaat bersamaan, dengan begitu hasil kerja yang dicapai kurang maksimal.

\section{Wewenang}

Dalam melaksanakan suatu tugas di Hotel,wewenang ini dapat dikatakan sebagai atasan dalam suatu organisasi yang mana sebagai sifat komunikasi antara karyawan Public Area dan atasannya yaitu Supervisor. Dalam hal ini Supervisor harus mampu memberikan beban kerja yang sesuai kepada bawahannya untuk mengerjakan suatu tugas yang harus dilaksanakan. Mengenai wewenang Supervisor di Hotel Batiqa Pekanbaru adalah Baik. Dikarenakan, atasan memiliki komunikasi yang baik di dalam timnya, dan juga memiliki solidaritas yang tinggi.

\section{Disiplin}

Disiplin atau taat terhadap peraturan yang telah disepakati dalam organisasi dimana ia bekerja perlu dilakukan oleh karyawan. Setiap karyawan harus memiliki sifat disiplin dalam dirinya, sehingga kedisiplinan mampu membuat dirinya terpacu untuk bekerja dengan baik, mengenai disiplin kerja karyawan Public Area di Hotel Batiqa Pekanbaru adalah Baik, dikarenakan disaat menangani Event karyawan Public Area di Hotel Batiqa Pekanbaru mampu menunjukan kedisiplinan kerja sesuai dengan SOP yang ada dan tidak bertele-tele dalam bekerja.

\section{Inisiatif}

Seorang karyawan Public Area di hotel Batiqa Pekanbaru harus mampu bersifat inisiatif dengan membentuk ide dan kreatifitas yang berkaitan dengan tujuan organisasi yang telah direncanakan oleh organisasi tersebut. Karyawan yang mampu memberikan ide yang baik tentu akan mampu membantu kelancaran pekerjaannya atau mampu membuat area tugasnya semakin di nikmati oleh tamu yang datang 
ke Hotel Batiqa Pekanbaru, mengenai inisiatif karyawan Public Area di Hotel Batiqa Pekanbaru adalah Cukup Baik, dikarenakan inisiatif atau ide atau kreatifitas pada diri seseorang atau individu tidak bisa semuanya timbul begitu saja. Namun karyawan di Hotel Batiqa dalam melakukan inisiatif kerja pada saat jam kerja sudah cukup untuk menunjang kerja yang dilakukan.

\section{SIMPULAN}

Public Area Attendant di Hotel Batiqa Pekanbaru mempunyai dua tugas yang harus dilakukan, yaitu sebagai Roomboy dan sebagai Public Area Attendant yang membuat karyawan Public Area mempunyai beban kerja yang membuat kinerja Public Area tersebut menjadi tidak efektif. Faktor kurangnya peralatan yang mendukung dan ditambah dengan banyaknya Event yang dilaksanakan hampir setiap hari di hotel tersebut membuat kinerja dari seorang karyawan Public Area tersebut menjadi kurang maksimal yang mengakibatkan tugas yang harus ia kerjakan menjadi lebih lama. Juga sebab kurangnya Karyawan Public Area di Hotel Batiqa Pekanbaru yang mengakibatkan menurunnya kinerja dari karyawan Public Area, sehingga karyawan Public Area tidak melaksanakan SOP pekerjaannya. Supervisor harus memberikan motivasi lebih kepada karyawannya agar mampu bekerja dengan baik.

\section{DAFTAR RUJUKAN}

Ahmad S Ruky. 2002. Sistem Manajemen Kinerja. PT Gramedia Pustaka Utama. Jakarta.

Agus Sulastiyono. (2011). Manajemen Penyelenggaraan Hotel: Manajemen Hotel. Bandung: Alfabeta.

Agus Sulastiyono. (2007). Teknik Dan Prosedur Divisi Kamar Pada Bidang Hotel. Bandung: Alfabeta
Agus Sambodo \& Bagyono, (2006). Dasar-dasar Kantor Depan Hotel. Yogyakarta. Andi

Arief. H. R. 2009. Buku Petunjuk Penyusunan Proposal dan Makalah. Akademi Pariwisata Engku Puteri Hamidah. Pekanbaru.

Any Noor.,2009,Manajemen Event. Alfabeta. Bandung

Bagyono,2009,Manajemen Housekeeping Hotel,Alfabeta,Bandung

Drs. A. Bambang Sujatno, CHA ,2008, Hotel Courtesy,Andi, Yogyakarta

Mathis,Robert,2007, Human Resources Management,Jakarta,Gramedia Pustaka

Prabu,Anwar,2010,Evaluasi Kinerja SDM,Jakarta,Refika Aditama

Perwani, Yayuk Sri. 2001. Teori dan Petunjuk Praktek Housekeeping untuk Akademi Perhotelan: Make Up Room. Jakarta: PT Gramedia Pustaka Utama.

Rumekso,SE,2008,Housekeeping Hotel Public Area/Houseman section,Andi,Yogyakarta

Rumekso, SE. 2002. Housekeeping Hotel,ANDI, Yogyakarta:

Sulastiyono, Agus.2011. Manajemen Penyelenggaraan Hotel.Seri manajemen Usaha Jasa Sarana Pariwisata dan Akomodasi. Alfabeta,cv.

Sedarmayati,2001,Sumber Daya Manusia Kerja,Madar Maju,Jakarta.Dan Produktivitas 
Yulia Novita, S.pd.i.,M.Par: 2016, Housekeeping Public Area. Dumai, Cv Mifan Karya Sekawan

http://letohotel.blogspot.co.id/2016/07/penge rtian-housekeeping-menurutpara.html

http://kerjakerasdapetduit.blogspot.co.id/201 5/12/tugas-dan-tanggung-jawabhousekeeping.html

https://glosarium.org/kata/index.php/term/tra vel-n-hotel,3834-high-seasonadalah.xhtml 